Лингвистика

DOI: $10.31862 / 2500-2953-2019-2-28-47$

\title{
K.A. Kepep
}

Челябинский государственный университет, 454001 г. Челябинск, Российская Федерация

\section{Диагностирующая стратегия отечественного и американского дискурса телевизионной медицинской драмы}

Статья представляет собой анализ реализации диагностирующей стратегии дискурса телевизионной медицинской драмы отечественной и американской лингвокультуры на материале телевизионных сериалов на медицинскую тематику «Практика» и "Grey`s Anatomy" («Анатомия Грэй») как наиболее ярких образцов данного вида дискурса. В исследовании освещается феномен медикализации, приводятся признаки жанра телевизионной медицинской драмы, дефиниция и признаки понятия медицинского дискурса, вводится в научный обиход понятие дискурса телевизионной медицинской драмы, а также рассматриваются способы достижения комплаенса на стадии диагностики в отечественном и американском дискурсе телевизионной медицинской драмы.

Ключевые слова: дискурс телевизионной медицинской драмы, медицинский дискурс, диагностирующая стратегия, медикализация, комплаенс.

ССЫЛКА НА СТАТЬЮ: Керер К.А. Диагностирующая стратегия отечественного и американского дискурса телевизионной медицинской драмы // Рема. Rhema. 2019. № 2. C. 28-47. DOI: 10.31862/2500-2953-2019-2-28-47. 
Rhema. Рема. 2019. № 2

DOI: 10.31862/2500-2953-2019-2-28-47

\section{K. Kerer}

Chelyabinsk State University,

Chelyabinsk, 454001, Russian Federation

\section{Diagnostic strategy of Russian and American television medical drama discourse}

The article analyzes the implementation of the diagnostic strategy of television medical drama discourse in Russian and American linguoculture on the material of the series "Practice" and "Grey's Anatomy" as the most striking examples of this type of discourse. The study highlights the phenomenon of medicalization and the genre of the television medical drama, introduces the concept of the medical drama television discourse and discusses it definitional properties, as well as the ways of achievement of compliance at the diagnostic stage in Russian and American medical drama television discourse.

Key words: television medical drama discourse, medical discourse, diagnostic strategy, medicalization, compliance.

CITATION: Kerer K. Diagnostic strategy of Russian and American television medical drama discourse. Rhema. 2019. № 2. Pp. 28-47. DOI: 10.31862/2500-2953-2019-2-28-47.

С возросшим значением медицины в современном обществе, которая переходит «из сферы профессиональных технологий в область идеологии, в пространство выстраивания фундаментальных культурных ориентиров» [Кириленко, 2009, с. 96-97], связан феномен медикализации. Специалисты в области здравоохранения в настоящее время все чаще привлекаются ко многим вопросам, связанными с переутомлением, стрессом, красотой и т.д., т.е. тем, что раньше не являлось предметом области медицины, но для современного человека становится более чем актуальным; он уверен, что только врач способен оказать квалифицированную помощь в этих аспектах, контролировать и регулировать их, что неизбежно приводит к следующему факту: «В свете нарастающего “перехватывания" культурой физиологических процессов, прежде 
бытовавших “естественно”, складывается ситуация, когда “родиться приходится в пробирке”, а санкцию на уход из жизни надо еще получить» [Серова, 2007, с. 63]. Вопросы медицины проникают в большинство сфер человеческой жизни; средства массовой информации освещают их, а телевидение не является исключением; медицинская драма как один из жанров телевизионного шоу - неопровержимое доказательство данного факта.

Объектом исследования является дискурс телевизионной медицинской драмы, продуцируемый в прототипической форме общения врача и пациента. Предметом изучения данной работы стали особенности языкового выражения диагностирующей стратегии данного вида дискурса. Цель работы - выявить и проанализировать особенности экспликации диагностирующей стратегии и соответствующих ей тактик дискурса телевизионной медицинской драмы, способы их реализации в анализируемом материале. Поставленная цель исследования предусматривает решение следующих задач: дать собственное определение понятия медицинского дискурса; ввести в научный обиход понятие дискурса телевизионной медицинской драмы; выделить характерные признаки данного типа дискурса; рассмотреть некоторые дефиниции термина дискурсивной стратегии, предложить собственное; дать определение понятия «диагностирующая стратегия дискурса телевизионной медицинской драмы», выявить особенности ее языкового выражения и тактики, способствующие этому; определить дискурсивную специфику прагматических типов предложений, использующихся в речи врача, выявить их грамматические характеристики; выявить языковые средства, способствующие успешной диагностике пациента, а также достижение комплаенса.

Для реализации поставленной в работе цели применялись такие методы, как описательный, включающий обобщение и классификацию анализируемого материала, и метод коммуникативно-прагматического анализа дискурса. Материалом исследования послужили транскрипты эпизодов 1-го сезона отечественного телевизионного фильма «Практика» и 7-го сезона американской телевизионной медицинской драмы “Grey`s Anatomy” («Анатомия Грэй»), выбор которых обусловлен принадлежностью к данному жанру, а также достаточной популярностью его в отечественной и американской лингвокультурах соответственно.

Медицинский дискурс, являющийся еще одной теоретической предпосылкой изучения дискурса телевизионной медицинской драмы, со своей проблематикой и вопросами, связанными с особенностями жанровой специфики, эффективностью взаимодействия между врачом и пациентом, способами воздействия врача на пациента, проблемами успешной 
коммуникации, границами суггестивности и т.д., привлекает внимание исследователей. М.И. Барсукова, Л.С. Бейлинсон, Т.Г. Карымшакова, Э.В. Акаева, Н.Д. Голев, Н.Н. Шпильная, Н.В. Гончаренко, В.В. Жура, Н.Ю. Сидорова, М.С. Невзорова и др. посвятили свои исследования этим вопросам. Данный вид дискурса, представляющий собой общение в рамках одноименного социального института, имеющее своей целью улучшение состояния здоровья пациента и, как следствие, и его жизни, играет значимую роль в современном обществе: каждый человек зависим от специалиста в области здравоохранения, к которому он обращается за медицинской помощью.

Под медицинским дискурсом нами будет пониматься вид институционального статусно неравноправного общения, участниками которого являются врач (или другой медицинский работник, принимая во внимание «разветвленную специализацию медиков как по горизонтали (специальности врачей), так и по вертикали (врачи - медицинские сестры - санитары)» [Барсукова, 2007, с. 21-22]), пациент, родственники пациента. Целью этого общения является диагностика заболевания, постановка диагноза, принятие методики лечения, оказание помощи обратившемуся за ней, а также рекомендации по предотвращению возможных последствий.

К характерным признакам медицинского дискурса мы можем отнести профессионализм, терминологичность, точность, диалогичность, суггестивность, эмпатию. Участниками медицинского дискурса (адресантами) являются специалисты области здравоохранения; адресатами пациенты, их родственники и окружение. Прототипическим местом общения в медицинском дискурсе можно считать стационар, больничную палату, кабинет врача. К целям медицинского дискурса можно отнести оказание врачебной помощи пациенту, поддержку родственникам, сбор анамнеза для постановки диагноза, выбор метода и способов лечения, рекомендации по профилактике рецидивов. Основной ценностью медицинского дискурса является здоровье человека.

Разновидностью медицинского дискурса, который может определяться узко как фрагмент медицинского телесериала, содержащий диалоги и полилоги врача, пациента, родственников обратившегося за помощью, коллег, видео-, аудиоряд и ситуацию общения; а также сам сериал на медицинскую тематику с участниками, непосредственно создателем и зрителем, с целью популяризации медицинской деятельности, сопереживания героям, попадающим в сложные ситуации, связанными с их профессиональной деятельностью, и прототипическим местом общения (больничной палатой, кабинетом специалиста, местом жительства героев и т.д.) мы называем дискурсом телевизионной медицинской драмы. 
В данной работе нами будет рассмотрен и определен данный вид дискурса как статусно неравноправное общение врача, пациента и его окружения, представленное такими коммуникативными событиями, как консультация врача, беседа с родственниками пациента в рамках телевизионного сериала на медицинскую тематику с целью развлечения зрителя посредством изображения повседневной жизни героев, попадающих в непростые ситуации, связанные с профессиональной деятельностью, описания клинических случаев, а также популяризации медицинской деятельности.

В коммуникативных диадах «врач - пациент», «врач - родственник пациента», триадах «врач - пациент - родственник пациента», «врач пациент - врач» и т.д. многие ученые отмечают асимметрию в сторону врача, который занимает активную позицию, обладает коммуникативной властью, основанной на авторитете, профессиональном знании. Это считается прототипическим образцом общения, характеризующим взаимоотношения внутри социального института медицины. Именно поэтому наше внимание остановлено на данном виде коммуникации. «Асимметрия связана с использованием директивных высказываний в сфере институционального общения, этому способствует статусно-ролевая принадлежность коммуникантов» [Кысмуратова, 2014, с. 3].

Одним из важнейших аспектов изучения дискурса телевизионной медицинской драмы, а именно диагностирующей стратегии данного вида дискурса, является вопрос о стратегиях коммуникативного взаимодействия субъектов.

Стратегии дискурса изучаются в разных научных областях: в когнитивной лингвистике (Т.А. ван Дейк, В. Кинч: «стратегия дискурса организация действий по достижению поставленной цели оптимальным путем» [Dijk, 1983, p. 62]), в лингвистике («стратегия как разновидность человеческой деятельности, которая имеет глубинную связь с мотивами, управляющими речевым поведением личности, и явную, наблюдаемую связь с потребностями и желаниями» [Иссерс, 1999,. с. 57]), в прагмалингвистике («совокупность речевых действий» [Труфанова, 2001, c. 58]), в психолингвистике («способ организации речевого поведения в соответствии с замыслом, интенцией коммуниканта» [Борисова, 1999, c. 85]), в формальной парадигме («это нормы и правила языка..., представленные в многочисленных учебниках, грамматиках и словарях» [Хомутова, 2015, с. 15]) и т.д.

Как справедливо замечает Л.В. Цурикова, некоторые «исследователи оперируют понятием дискурсивной стратегии, понимая под стратегиями потенциально возможные интерактивные способы осуществления коммуникативно значимых действий в дискурсе и языковые способы 
их выражения. Выбор определенных средств для достижения определенной цели говорящего в определенных условиях общения рассматривается как реализация определенной стратегии в дискурсе» [Цурикова, 2007, с. 101].

М.С. Невзорова опирается «на понимание стратегии как комплексного речевого воздействия, обусловленного определенной целью высказывания и реализуемого посредством различных речевых тактик» [Невзорова, 2017, с. 158].

Т. ван Дейк, характеризуя стратегию как «свойство когнитивных планов» [Дейк, 2000, с. 272], представляющих общую организацию последовательности действий, согласованных с целью взаимодействия, справедливо поднимает вопрос об эффективности такого стратегического планирования коммуникации. «Оптимальное достижение цели является одним из типичных проявлений “хорошей” стратегии; при этом либо достигается максимальное количество целей, либо достижение каждой из целей осуществляется, насколько это возможно, в соответствии с желаниями или предпочтениями, стоящими за планом действий» [Там же].

М.Л. Макаров понимает под коммуникативной стратегией непостоянную, динамичную единицу коммуникации, «ведь в ходе общения она подвергается постоянной корректировке, непосредственно зависит от речевых действий оппонента и от постоянно пополняющегося и изменяющегося контекста дискурса. Динамика соотношения осуществляемого в данный момент хода с предшествующими, а также их влияние на последующие - один из главных признаков стратегии» [Макаров, 2003, с. 194].

Е.В. Клюев, определяя понятие коммуникативной стратегии, говорит о совокупности теоретических ходов, которые заранее запланированы говорящим. Коммуникативная тактика представляет собой «совокупность практических ходов в реальном процессе взаимодействия» [Клюев, 2002, с. 18]. Если коммуникативная стратегия, по мнению ученого, соотносится с коммуникативной целью, то тактика соотнесена с «набором коммуникативных намерений» [Там же, с. 19].

В данной работе мы принимаем следующее определение стратегии дискурса телевизионной медицинской драмы: это линия коммуникативного поведения врача, имеющая целью постановку диагноза, сбор анамнеза, сообщение о диагнозе, необходимом лечении и рекомендациях, особым образом организованную, имеющую речевые тактики в качестве средств воплощения в рамках телевизионного медицинского шоу.

К специфическим особенностям жанра телевизионной медицинской драмы можно отнести следующее: 
1) большое количество серий, объединенных общей сюжетной линией; материал нашего исследования представляют собой сериалы так называемого «вертикального» формата: главные герои неизменны, однако в каждой серии они попадают в различные ситуации, соответственно, зритель, вне зависимости от того, когда он приступил к просмотру, не потеряет нити повествования;

2) коммуникативная направленность: телевизионная медицинская драма описывает знакомые зрителю жизненные ситуации (прием у врача, сложность принятия решений, связанных со здоровьем близких и своего собственного, и т.д.);

3) сходность приемов общения и моделей поведения персонажей и зрителей;

4) воспроизведение в художественной форме особенностей профессиональной деятельности медицинского персонала;

5) демонстрация способов выстраивания отношений врача и пациента, коллег;

6) присутствие визуальных и вербальных клише;

7) создание специфической картины мира;

8) акцент на вербальном тексте: герои телевизионной медицинской драмы ведут образ жизни, сходный зрителю, говорят на бытовые темы;

9) общедоступность (ориентация на широкую аудиторию);

10) занимательность: зритель вовлечен в процесс повествования, сопереживает героям, следит за перипетиями их личной жизни, а также профессиональной деятельности;

11) коммерческая нацеленность;

12) акцентуация на внутренний мир действующих лиц: каждый эпизод медицинской драмы имеет целью рассмотрение определенного клинического случая, который является фоном для раскрытия личностных особенностей героев;

13) отсутствие у зрителя правильной интерпретации, что порождает идеи развития будущих событий по информации из прошлых серий;

14) фрагментированную нарративную структуру: каждая серия обязательно имеет завязку, развитие сюжета, а также финальную часть.

Соглашаясь с такими исследователями, как В.И. Карасик, Л.С. Бейлинсон, М.И. Барсукова, выделявшими три основные стратегии медицинского дискурса: диагностирующую, лечащую и рекомендующую, мы полагаем, что дискурс телевизионной медицинской драмы, являясь разновидностью медицинского дискурса, также эксплицируется ими, вследствие чего нами будет рассмотрена реализация диагностирующей стратегии как одной из основных в общении врача и пациента / его окружения, имеющей особое значение в процессе оказания помощи больному, 
постановке диагноза, дальнейшего лечения в случае необходимости, т.к. именно на данной стадии силами специалиста достигается комплаенс согласие на необходимые манипуляции, лечение и т.д.

Умение врача общаться с пациентом, его родственниками или другими членами окружения обеспечивает эффективность диагностики. В случае доверия специалисту, достижения комплаенса, пациент легко пройдет все необходимые диагностические процедуры; соответственно, на данной стадии коммуникативная компетенция врача должна включать в себя умение наладить контакт с пациентом, слушать, задавать необходимые для точной постановки диагноза вопросы определенного типа, контролировать свои чувства, сохранять уверенность, быть толерантным, обладать эмпатией, а также умением сочетать физический контакт с пациентом и процесс вербальной коммуникации, мотивировать больного к прохождению необходимых диагностических манипуляций, вселить в него уверенность в успех, подстроить собственную апперцепционную базу под апперцепционную базу пациента с целью быть ему понятным.

Рассмотрим примеры вербализации диагностирующей стратегии дискурса телевизионной медицинской драмы в анализируемом образце отечественного телевизионного шоу «Практика», начав с эпизода, отображающего первичный прием пациента, обратившегося за помощью к специалисту.

В рач 1: Так, здравствуйте (ритуализированная формула приветствия). Контактоподдерживающее средство так является, с одной стороны, способом выражения коммуникативной дистанции, лидирующей позиции специалиста, доминирования над пациентом, сигналом вступления в коммуникацию, и с другой - демонстрирует заинтересованность врача в осмотре пациента. Формула приветствия обычно используется на этапе диагностики с целью установления доброжелательных отношений, усиления суггестивного воздействия и достижения комплаенса. Дина вас зовут, да? Частица да-средство поддержания контакта, получения обратной связи. Данный квеситив, помимо функции получения нужной информации, сокращает коммуникативную дистанцию между врачом и пациентом, демонстрирует эмпатию. Очень приятно (тактика сближения). Тактика сближения, знакомства является важной при диагностике пациента: она помогает наладить контакт, внушить доброжелательное отношение, тем самым достичь комплаенса. Ну, я смотрю, у вас серьезное воспаление, судя по анализам (тактика вынесения диагностического заявления на основе проведенных манипуляций, осмотра). Может, вы нам скажете, где у вас болит? (тактика запроса информации). Вводное словосочетание может снижает категоричность высказывания, а также свидетельствует о возможном 
допущении отсутствия положительного ответа. Понимая, что пациентка стесняется разговаривать с врачом, боится предстоящего осмотра и возможных откровенных вопросов, специалист осознает необходимость проведения диагностики и задает специальный вопрос открытого типа для определения локализации болей и последующей постановки диагноза. Соответственно, к дискурсивной функции квеситива, состоящей в получении релевантной информации, добавляется функция снижения категоричности высказывания.

Паци ентка: Мне неудобно. В данном коммуникативном эпизоде мы наблюдаем ситуацию, при которой пациент старается избежать откровенного разговора, перехода к неприятным для него вопросам, которые являются темой для беспокойства, и т.д. Следовательно, врачу необходимо сменить тактический ход для расположения пациента. И он выбирает тактику комплимента:

В рач 1: Скромность украшиет девушек, но не в данную секунду. Делая комплимент, врач одновременно использует тактику внушающего наставления, синтаксическим средством реализации которой является сложноподчиненное предложение с противительным союзом. Наставление создает определенный настрой во время диагностики, демонстрирует коммуникативное доминирование, готовит пациента к совершению определенного поведенческого акта. Продолжая поддерживать позицию коммуникативного лидера, специалист возвращается к предыдущему вопросу, однако понимая, что врач должен проявлять доброжелательное отношения к пациенту, тактичность, избегать конфликтных ситуаций, прагматический тип предложения меняется, переходя от квеситива к императиву с частицей все-таки, снижающей категоричность высказывания: Bы все-таки, скажите нам, где у вас болит.

П а ц и е н т ка: Грудь.

В рач 1: $A$-a. Данный коммуникатив является средством поддержания контакта с пациентом, а также средством выражения внимания и понимания. A вы делали маммопластику, да? (тактика формулирования хода мыслей пациента, эксплицированная квеситивом в форме вопроса-повтора). Использование данного типа вопроса детерминировано коммуникативными и личностными особенностями пациентки. Врач считает использование медицинской терминологии оправданным вследствие схожести апперцепционных баз с пациенткой: она недавно перенесла данное оперативное вмешательство. Когда? (тактика уточнения, выраженная специальным эллиптическим вопросом).

П а ц и е н т а: Да, месяц назад. Понимаете, мой молодой человек, 
В рач 1: Но вы знаете, вот я вижу, что болит-то у вас не со вчерашнего дня, правильно? (тактика формирования хода мыслей пациента) Врач пытается стабилизировать его эмоциональное состояние. Тактика эксплицирована прерванными синтаксическими конструкциями, инверсией. Задавая вопрос-провокатор, специалист, с одной стороны, пытается внушить пациенту невозможность другой формулировки, вследствие чего тот вынужден согласиться, а с другой - хочет получить согласие/ несогласие с этой формулировкой для подтверждения/опровержения своего хода мыслей по поводу возможного диагноза. Данная синтаксическая конструкция является также средством достижения комплаенса методом воздействия на общий настрой пациента, который должен быть уверен в том, что ему помогут. Наряду с получением релевантной информации, дискурсивной функцией квеситива является контроль за темой обсуждения. А почему вы не обратились в клинику, где вам делали операцию? (тактика запроса информации, эксплицированная вопросом-путеводителем для стимулирования речевой активности пациента).

П а ц и е н т к а: Но там бы опять пришлось платить, а Георгий и так потратился. Я не хотела его расстраивать.

В рач 2: Можете показать? (тактика получения разрешения на осмотр) Врач использует косвенную побудительную конструкцию, что лишает его категоричности, а также является показателем вежливости. Покажите (команда, выраженная императивом, вербализованная глаголом в повелительном наклонении). Обычно команды врача не воспринимаются как психологическое давление на пациента, несмотря на то, что они лишают его свободы выбора. В этом проявляется коммуникативная позиция лидера. Ага (коммуникатив, комментирующий совершаемые врачом/пациентом действия, при помощи которого специалист поддерживает контакт с пациентом).

Паци ентка: Понимаете, он стал смотреть на других женщин. Я хотела что-то сделать для него.

В р а ч 1: Я понимаю (тактика выражения эмпатии), но, к сожалению, вы знаете, это похоже на сепсис и нам придется сделать операцию и вынуть имплант (тактика предупреждения). Врач ставит пациента в известность о своих дальнейших действиях. Данная тактика эксплицирована экспозитивом в форме глагола со значением долженствования. Использование прерванных синтаксических конструкций свидетельствует об эмпатии врача. Иначе, ну... (тактика предупреждения) $H y$, если вы не против (тактика сотрудничества).

П а ц и е н т к а: Hy, хорошо. 
В проанализированном коммуникативном эпизоде мы наблюдаем, что врач при реализации диагностической стратегии довольно эмоционален вследствие использования коммуникативов; он дает понять пациенту, что его слышат, его проблема важна, и она будет решена все это необходимо для достижения комплаенса. Диагностику специалист начинает с ритуализированной формулы приветствия, обращается к пациенту по имени, что способствуют установлению доброжелательных отношений с пациентом и последующему достижению комплаенса. Врач пытается сблизиться и поддержать контакт, выражая эмпатию; предупреждает о своих дальнейших действиях, пытается сотрудничать с пациентом, спрашивая разрешение на осмотр, снимает категоричность своих высказываний использованием косвенных императивов.

Следующий коммуникативный эпизод - прототипический образец реализации диагностирующей стратегии отечественного дискурса телевизионной медицинской драмы - осмотр пациента, поступившего в приемное отделение больницы с травмами.

В рач 1: Ну вот, ничего страшного (тактика поддержания эмоционального равновесия). Диалог врача и пациента начинается не с формулы приветствия, ведь местом действия - не прием врача в поликлинике, а осмотр пациента в приемном отделении больницы. У вас просто сильный ушиб (тактика вынесения диагностического заявления). Данное высказывание специалиста является экспозитивом, дискурсивная специфика которого состоит в сочетании интенции предоставления неизвестной до этого момента информации с воздействием на адресата. Данный экспозитив является объяснением, основной дискурсивной функцией которого является, ввиду наличия наречия просто, коррекция эмоциональных проявлений пациента. Сейчас мы вам наложим фиксирующую повязку, обезболим, и можете идти домой (тактика объяснения). В процессе диагностирования для пациента важно, чтобы ему разъяснили, что его ждет, будет ли это болезненно, в результате чего он сможет чувствовать себя спокойнее, а врач, свою очередь, сможет перейти к процессу лечения.

Паци ент: Доктор, можно я пойду на воздух куда-нибудь? Мне очень жарко здесь у вас.

В р а ч 2: Дина, что с вами? Как вы себя чувствуете? (тактика запроса информации) Открытые вопросы, позволяющие пациенту давать ответы в свободной форме, задаются специалистом не только с целью получения требуемой для постановки верного диагноза информации, но и для выражения эмпатии.

В ра ч 1: Уx, mbl! Восклицание, выражающее удивление специалиста, также является способом демонстрации внимания к проблеме пациента, 
способом достижения комплаенса. Да у вас жар! (тактика вынесения диагностического заявления на основе осмотра) Скажите, а до происшествия Вын ничем не болели? Я имею в виду простуду или какие-то воспалительные процессы? (тактика запроса информации). Вопросы-путеводители используются для стимулирования речевой активности пациента, выводя на желательную перспективу беседы и возвращая пациента к ней.

В р а ч 2: Ложитесь, ложитесь (императив). Команда врача способствует выработке у пациентки автоматизма действий. Пациент выполняет их, не раздумывая, доверяя словам специалиста как сигналу к действию. Характерная черта врачебной команды - ее исполнение даже тогда, когда требование аналогичного содержания вызвало бы сопротивление в другой ситуации. Повтор является средством снижения категоричности высказывания и средством достижения комплаенса.

Паци ентка: Я не знаю. Просто это с утра началось. Какие-то непонятные ощущения: голова как в тумане, и жарко, и холодно одновременно.

В ра ч 1: То есть с ногой это не связано? (тактика получения релевантной для постановки диагноза информации, эксплицированная уточняющим вопросом сочетается с тактикой возврата диалога в прежнее русло). Таким образом, еще одной дискурсивной функцией квеситива является обеспечение коммуникативного доминирования специалиста.

П а ц и е н т: Я не знаю.

В рач 1: Так, ну анализы у вас, прямо скажем, не очень: повышенные лейкоциты, СОЭ (тактика объяснения). Коммуникатив так - средство демонстрации социальной дистанции между врачом и одновременно средство выражения внимания специалиста к проблеме пациента, эмпатии. Одним из главных отличительных признаков тактики объяснения является наличие аргументативного компонента, выраженного специальной лексикой, характеризующегося элементами научного стиля, логичностью. Терминоупотребление предназначено в данном случае для демонстрации и внушения пациенту компетентности специалиста. У вас явный воспалительный процесс (тактика вынесения предварительного диагноза на основании данных анализов). Может, вас все-таки что-то беспокоит? (тактика возврата диалога в нужное русло). Вводное словосочетание может снижает категоричность высказывания, является средством проявления эмпатии, достижения комплаенса. Пригласите Евгению Павловну.

В проанализированном коммуникативном эпизоде можно наблюдать подтверждение того, что диагностика заключается не только в сборе сведений анамнеза, но и в осмотре пациента, во время которого врач, 
говоря о здоровье пациента, старается поддержать эмоциональное равновесие, сообщает информацию о дальнейших действиях, выражает эмпатию. Команды врача, выраженные императивами, имеют сниженную категоричность благодаря повторам.

В рач 1: Давайте рубашку снимем, тихонечко (тактика смягчения высказывания). Данная реплика специалиста является способом выражения вежливости ввиду наличия транспонированного значения лица глагола и частицы давайте, которая выражает значение совместного участия в действии говорящего и собеседника. Наречие с семантикой незначительности, диминутив является еще одним средством смягчения высказывания, выражения доброжелательного отношения. Категоричность императива, призванного организовать действия пациента с целью регулировки их поведения на этапе диагностики, здесь снижена.

П а ц и е н т: $O x$ mbl, oй-oü, aй.

В рач 1: Да уж, повезло так повезло (тактика оценки). Специалист выражает свою оценку не напрямую, а используя эвфемизм. Пациент обращается к врачу не по собственному желанию, а по необходимости, соответственно, специалист должен предпринять усилия к созданию доверительной атмосферы сотрудничества. Похоже, у вас плечо выбито, и рука сломана (тактика вынесения предварительного заключения на основании осмотра).

Пациент: Ой, осторожно! Что уж теперь-то, снявии голову, по волосам не плачут, как говорят. При рассмотрении тактик диагностирующей стратегии дискурса телевизионной медицинской драмы одним из важных моментов является анализ их реализации в случаях языковой игры, основанной на модификации базовых форм фразеологизмов и паремий, а также случаев использования фразеологизмов в их базовых формах. Пациент, понимая, что вынесенное специалистом диагностическое заключение не является положительным, не может добавить ничего, кроме как привести в качестве примера идиоматическое выражение.

В р а ч 1: Ну, голова у вас, слава богу, целая, но с рукой, кажется, придется повозиться (тактика объяснения в сочетании с тактикой достижения эмоционального равновесия). Использование литоты придется повозиться позволяет врачу стабилизировать эмоциональное состояние пациента, не дать ему переживать по поводу самочувствия. Синтаксическим средством реализации данной тактики является сложносочиненное предложение с противительным союзом.

П а ц и е н т: Ничего, заживет, как на собаке. В тюрьме кривая пригодится, и посадят на всю оставиуюся жизнь, фух. 
В р а ч 1: Это что, вы за рулем, что ли были? (тактика демонстрации внимания к проблемам пациента). Вставки в диалоге врача и пациента на темы, не связанные с общей темой беседы, помогают также воздействовать на общий настрой пациента, отвлечь его от переживаний по поводу своего самочувствия.

Па ц и ен т: Я былл, Я.

В р а ч 1: М-м, поэтомуя не езжу на маршрутках: с ужасом смотрю, как вы водите (тактика объяснения). Синтаксическим средством выражения данной тактики является распространенная конструкция с аргументативной частью.

Паци ент: Да я-то не при чем, какая-то ненормальная на дорогу выскочила, еще и с ребенком. Что, мне ее теперь давить что ли? И так всегда: пешеход виноват, сидит водитель, нормально.

В ра ч 1: Ну, вы же должны понимать, что дорога - это зона повышенного риска (тактика внушающего наставления).

П а ц и е н т: Ну да, ну да.

В ра ч 1: Сейчас я вам обезболивающее вколю (тактика предупреждения о своих дальнейших действиях).

П а ц и е н т: Да не надо, я приучен к боли.

Специалист при реализации диагностирующей стратегии смягчает свои императивные высказывания, использует наречия с семантикой незначительности, частицу давайте и транспонированное значение лица глагола, выражая эмпатию.

Рассмотрение особенностей вербализации диагностирующей стратегии дискурса телевизионной медицинской драмы продолжим на примере американской лингвокультуры, начиная с одного из прототипических образцов, иллюстрирующих прием пациента.

В р а ч 1: See? (тактика контроля понимания). Синтаксическим средством выражения данной тактики является квеситив. Специалисту важно, осознает ли пациент, о чем идет и речь и видит ли то, что хочет показать врач, это один из способов достижения комплаенса. You went down before the lightning even struck (тактика объяснения). Способ экспликации тактики - констатив.

П а ц и е н т к а: Oh, my God. Warren. I never even saw him coming.

В ра ч 2: Kerry, your new scan shows an epidural hematoma. It's blood in your spine that's compressing your spinal cord (тактика объяснения). Специалист открывает пациентке суть механизмов, лежащих в основе ее проблемы с состоянием здоровья, пытаясь привлечь к будущему процессу лечения. Обращение к ней по имени демонстрирует сочувственное отношение, эмпатию. 
П а ц и е н т ка: And I'll walk again?

В рач 2: You'll be out on the field in no time (тактика внушения). Способом экспликации данной тактики является промисив. Основной целью тактики является воздействие на подсознание и эмоциональное состояние пациента. (Врачу 1): Book an O.R.

Далее специалист получает от старшего коллеги команду и начинает ее выполнять. В ситуации дефицита времени, тяжести состояния пациента и т.д. вербального подтверждения получения команды не предполагается; профессионализм O.R. заменяет медицинский термин, сокращает время и упрощает понимание между коллегами. Как видно из вышеописанной коммуникативной ситуации, диагностирующая стратегия суггестивна: для достижения комплаенса врач внушает пациенту мысли о скорейшем выздоровлении, используя такой прагматический тип предложения, как промисив. Врач подтверждает для себя осознание пациентом его слов использованием квеситива.

Следующий эпизод - один из прототипических образцов работы команды специалистов-медиков, которая регулируется акциональнопрактической целью оказания помощи пациенту:

В рач 1: Decreased breath sounds on the right side (тактика предоставления релевантной информации о состоянии пациента на основании предварительного осмотра). Um, so is there any chest pain or is it just difficulty breathing? (тактика получения релевантной информации о состоянии здоровья пациента). Альтернативный вопрос задан врачом с целью уточнения характера симптомов. Данная форма запроса информации врачом служит пациенту импульсом к актуализации понятия заболевания.

П а ц и е н т: Uh, it's... it's kinda both. It's cancer. Пациент актуализирует заболевание эксплицитно: он называет свой диагноз, используя терминологическую номинацию.

Р одс тв енни и пациен тки: It's not cancer.

П а ц и е н тк а: Ooh, it's cancer or it's, um... Anxiety about the wedding. Категоричность выказывания уменьшена.

В рач 2: Oh, when are you getting married? (тактика запроса информации). Обсуждение даты бракосочетания пациентки осуществляется в рамках прагматической тактики демонстрации внимания к пациенту, желания сократить социальную дистанцию между врачом и пациентом. То есть данный квеситив выполняет дискурсивную функцию сближения.

П а ц и е н т ка: Two weeks.

В рач 1: Well, we're gonna need to get a chest X-ray (тактика предоставления информации о ходе диагностики). Перформатив выражает намерение врача провести определенные манипуляции. So is there any 
chance that you could be pregnant? (тактика смягчения высказывания). В данном случае врач пытается получить необходимую для постановки диагноза информацию, смягчая высказывание, затрагивая откровенный вопрос, снижая лицеущемляющий эффект. То есть дискурсивная специфика квеситива проявляется в реализации таких коммуникативных целей, как получение врачом релевантной информации, а также снижения лицеущемляющего эффекта.

П а ц и ен тка: Oh... Mnh-mnh. Not pregnant. Пациент, используя односоставное предложение, паузы, выражает замешательство.

В р а ч 2: You're sure? (тактика контроля понимания). Заметив смущение, формальность ответа пациентки, желание избежать откровенного разговора по определенной причине, врач вынужден применить другой тактический ход: он задает уточняющий вопрос-провокатор, который призван убедить его в отрицательном ответе для того, чтобы отсечь один из возможных диагнозов пациентки. Дискурсивная функция данного квеситива - уточнение информации, которая является релевантной на стадии постановки диагноза для выбора дальнейших диагностических манипуляций. Инверсия, придающая данному высказыванию разговорный характер, является средством сокращения коммуникативной дистанции между врачом и пациентом.

Р о д с т в е н н и к п а ц и н т к и: She `s sure. Диагностирующая стратегия дискурса телевизионной медицинской драмы эксплицируется также тактиками запроса информации для сближения с пациентом, предоставления информации о ходе диагностики в форме перформатива, смягчения высказывания, выраженного квеситивом; врач пытается объяснить пациенту суть предстоящих манипуляций, избежать лицеущемляющего эффекта от задаваемых вопросов и т.д. для того, чтобы получить согласие от него на дальнейшую диагностику и лечение.

В следующем образце дискурса телевизионной медицинской драмы мы будем наблюдать ситуацию, при которой, диагностируя состояние здоровья пациента, врач одновременно стремится изменить его картину мира, объясняя причины состояния здоровья:

В р а ч 1: Um, Mr. Adams, sometime in your history, you contracted H.P.V. (тактика контроля за релевантностью информации, эксплицированная констативом). There are various types of the virus. This one generally causes small warts. There is an immune deficiency that allows the warts to get out of control (тактика объяснения). Экспозитив в форме пояснения направлен на устранение дефицита информации у пациента и/или его родственников, членов окружения. Необходимым условием успешной профессиональной деятельности специалистов области здравоохранения является использование в речи медицинских терминов, 
т.к. именно они дают точное определение предметам и явлениям в медицинской практике. Е.И. Голованова понимает под термином «вербализованный результат профессионального мышления, значимое лингвокогнитивное средство ориентации в профессиональной сфере и важнейший элемент профессиональной коммуникации» [Голованова, 2011, с. 58]. «Термину противопоказаны экспрессия, побочные ассоциации и прочие черты, свойственные художественному слову» [Шкарин, 2004]. Их использование в профессиональном общении не предполагает факт объяснения значения, учитывая то, что знание медицинской терминологии и свободное применение ее в речи входит в коммуникативную компетенцию специалиста-медика и может служить средством его самопрезентации, указывая на высокую профессиональную компетентность.

Ж ен а п ц и е н а: We went to a dermatologist in Pullman four years ago. They were a lot smaller then. He removed a bunch of them, but...

П а ц и е н т: ... they grew back. Then we saw the guy again, and they grew back again. They're always gonna grow back. And that's why we should just go home.

В р а ч 1: Well, if you don't do anything about it, they're gonna continue to grow. You'll become completely disabled (тактика преувеличения тяжести состоянии пациента, главным средством реализации которой является предикативная лексема со значением «стать инвалидом»). We need to do surgery (тактика экспликации причинно-следственных связей, вербализуемая сложноподчиненным предложением с придаточным условия).

Ж е н а п а ц и н т а: You can't just scrape the stuff off?

В рач 2: No. Um, each one of the warts has its own blood supply. So we need to cut and stitch each one (тактика объяснения). Она имеет еще одну особенность и функцию: с ее помощью врач готовит пациента к получению релевантной информации о диагнозе, будущих необходимых манипуляциях. Для того чтобы восприятие пациента смягчилось, врачу необходимо дать объяснение процессам, происходящим в его организме. Специальная лексика, безэмоциональность способствуют достижению поставленной коммуникативной цели. Основным грамматическим признаком данной речевой формы - прескриптива - является будущее время, а пропозиционным содержанием - будущие действия врача.

П а ц и е н т: So basically, I'm gonna go from looking like a tree to looking like Frankenstein, right? Super.

В рач 1: Well, we'll be doing skin grafts at the same time, which will help with your appearance and function. That's said, you're right, it's not a cure. The warts will recur, but if you schedule surgeries regularly, we might be able to keep them under control (тактика утешения). Она имеет целью смягчить мнение пациента о предстоящем оперативном вмешательстве, 
основными лексическими маркерами которой являются лексемы со значением улучшения, нормализации, а также модальный глагол will. Врач пытается оптимизировать эмоциональное состояние пациента, отвлекая его внимание от беспокойств по поводу внешнего вида.

В ходе анализа материала было установлено, что при реализации диагностирующей стратегии дискурса отечественной телевизионной медицинской драмы врач пользуется вопросительными высказываниями, выполняющими разнообразные коммуникативно-прагматические функции: запроса информации, возвращения к прежней теме, указания на желательную перспективу диалога. Наиболее частотной является тактика запроса информации, эксплицированная вопросами различных типов с разными коммуникативно-прагматическими функциями, зачастую снижая категоричность высказываний: формулировки хода мыслей пациента, уточнения, возврата диалога в нужное русло, стимулирования речевой активности пациента, получения разрешения на осмотр. Специалисты достаточно эмоциональны, используют контактоподдерживающие средства, ритуализированные формулы приветствия, способны говорить с пациентом на отвлеченные темы, проявляя эмпатию и достигая комплаенса. Что касается речевых форм реализации диагностирующей стратегии, то нами были выделены констативы, квеситивы, основная цель которых заключается в получении необходимой информации, сокращении коммуникативной дистанции между врачом и пациентом, демонстрации эмпатии, снижении лицеущемляющего эффекта и т.д.

Во время диагностики американский специалист безэмоционален, убедителен; используя тактику экспликации причинно-следственных связей, он поясняет пациенту необходимость применения определенных диагностических манипуляций и лечебных процедур, использует специальную лексику, контролирует релевантность информации при помощи констативов. Американские специалисты, как показал анализ, не используют ритуализированных формул приветствия, как мы полагаем, вследствие такой профессионально-культурной ценности американской лингвокультуры, как ценность времени, а также ввиду того, что процесс диагностики проходит в условиях стационара, а не амбулатории.

Арсенал средств вербализации диагностирующей стратегии отечественного и американского дискурса телевизионной медицинской драмы различен, они осуществляются разным набором тактик, выполняющих разнообразные дискурсивные функции, равно как и способы достижения комплаенса. Однако все они направлены на установление верного диагноза и улучшение психоэмоционального состояния пациента. 


\section{Библиографический список / References}

Барсукова, 2007 - Барсукова М.И. Медицинский дискурс: стратегии и тактики речевого поведения врача: Дис. ... канд. филол. наук. Саратов, 2007. [Barsukova M.I. Medicinskij diskurs: strategii i taktiki rechevogo povedeniya vracha [Medical discourse: Strategies and tactics of doctor's speech behaviour]. PhD dis. Saratov, 2007.]

Борисова, 1999 - Борисова И.Н. Категория цели и аспекты текстового анализа // Жанры речи: Сб. науч. ст. Саратов, 1999. Вып. 2. С. 81-97. [Borisova I.N. Category of aim and aspects of text analysis. Zhanry rechi. Collection of scientific articles. Saratov, 1999. Vol. 2. Pp. 81-97.]

Голованова, 2011 - Голованова Е.И. Введение в когнитивное терминоведение: Учебное пособие. М., 2011. [Golovanova E.I. Vvedenie v kognitivnoe terminovedenie [Introduction to cognitive science of terminology]. Moscow, 2011.]

Дейк, 2000 - Дейк Т.А. ван Язык. Познание. Коммуникация. Благовещенск, 2000. [Dejk T.A. van. Yazyk. Poznanie. Kommunikaciya [Language. Cognition. Communication.]. Blagoveschensk, 2000.]

Иссерс, 1999 - Иссерс О.С. Коммуникативные стратегии и тактики русской речи. Омск, 1999. [Issers O.S. Kommunikativnye strategii i taktiki russkoj rechi [Communicative strategies and tactic of Russian speech]. Omsk, 1999.]

Кириленко, 2009 - Кириленко Е.И. Концепт медикализации культуры как опыт социокультурной интерпретации // Дефиниции культуры. Томск, 2009. C. 96-101. [Kirilenko E.I. Concept of cultural medicalization as an experience of sociocultural interpretation. Definicii kul'tury. Tomsk, 2009. Pp. 96-101.]

Клюев, 2002 - Клюев Е.В. Речевая коммуникация. Успешность речевого взаимодействия. М., 2002. [Klyuev E.V. Rechevaya kommunikaciya. Uspeshnost' rechevogo vzaimodejstviya [Speech communication. The success of speech interaction]. Moscow, 2002.]

Кысмуратова, Ниетбайтеги, 2014 - Кысмуратова Ж.Т., Ниетбайтеги К.А. Лингвистические особенности медицинского дискурса // Наука и образование: новое время. 2014. № 1. 2014. С. 48-52. [Kysmuratova Zh.T., Nietbajtegi K.A. Linguistic peculiarities of medical discource. Nauka i obrazovanie: novoe vremya. 2014. № 1. 2014. Pp. 48-52. ]

Макаров, 2003 - Макаров М.Л. Основы теории дискурса. М., 2003. [Makarov M.L. Osnovy teorii diskursa [Basics of discource theory]. Moscow, 2003.]

Невзорова, 2017 - Невзорова М.С. Коммуникативная ситуация устного профессионального общения в рамках англоязычного медицинского дискурса // Научный диалог. 2017. № 3. С. 68-80. [Nevzorova M.S. Communicative situation of oral professional communication in English medical discource. Nauchnyj dialog. 2017. № 3. Рp. 68-80.]

Серова, 2007 - Серова И.А. Медикализация культуры - вектор развития? // AНTPО: Анналы научной теории развития общества. Пермь, 2007. С. 60-67. [Serova I.A. Culture medicalization - development vector? ANTRO: Annaly nauchnoj teorii razvitiya obshchestva. Perm, 2007. Pp. 60-67.]

Труфанова, 2001 - Труфанова И.В. О разграничении понятий: речевой акт, речевой жанр, речевая стратегия, речевая тактика // Филологические науки. 2001. № 3. C. 56-65. [Trufanova I.V. About differentiation of notions: illocutionary act, speech genre, speech strategy, speech tactic. Filologicheskie nauki. 2001. № 3. Pp. 58.] 
Хомутова, 2015 - Хомутова Т.Н. Стратегии научного дискурса: интегральный подход // Вестник Южно-Уральского государственного университета. Серия «Лингвистика». 2015. Т. 12. № 3. С. 15-22. [Homutova T.N. Scientific discource strategies - integral approach. Bulletin of South Ural State University. Series "Linguistics". 2015. Vol. 12. № 3. Pp. 15-22.]

Цурикова, 2007 - Цурикова Л.В. Дискурсивные стратегии как объект когнитивно-прагматического анализа коммуникативной деятельности // Вопросы когнитивной лингвистики. 2007. № 4 (013). C. 98-108. [Curikova L.V. Discoursive strategies as an object of cognitive-pragmatic communicative activity analysis. Issues of Cognitive Linguistics. 2007. № 4 (013). Pp. 98-108.]

Шкарин, Григорьева, Горохова, 2004 - Шкарин В.В., Григорьева Ю.В., Горохова Н.М. О культуре использования научной медицинской лексики (терминологии). 19.01.2004. URL: http://www.medicum.nnov.ru/nmj/2004/1/31.php (дата обращения: 10.02.2018) [Shkarin V.V. O kul'ture ispol'zovaniya nauchnoj medicinskoj leksiki (terminologii) [About culture of using scientific medical vocabulary]. URL: http://www.medicum.nnov.ru/nmj/2004/1/31.php]

Dijk, Kintsch, 1983 - Dijk, van T.A., Kintsch W. Strategies of Discourse Comprehension. New York, 1983.

Статья поступила в редакцию 17.02.2019

The article was received on 17.02.2019

\section{Сведения об авторе / About the author}

Керер Ксения Александровна - кандидат филологических наук; старший преподаватель кафедры делового иностранного языка факультета лингвистики и перевода, Челябинский государственный университет

Kseniya A. Kerer - PhD in Philology; senior tutor at the Business Foreign Language Department of the Faculty of Linguistics and Translation, Chelyabinsk State University

E-mail: ksenijakerer@rambler.ru 